\title{
Research on Economics Teaching Mode of Individualized learning based on mobile Internet
}

\author{
Zhangrui \\ Jilin Business and Technology College \\ Zhengyang street No.1761, Ivyuan district, Changchun, China \\ 33388960@qq.com
}

Keywords: Individualized Learning, Mobile Internet, Economics, Teaching Mode

\begin{abstract}
This paper summarizes the literature and based on the analysis of the meaning of personalized learning, and a comprehensive understanding of the meaning and characteristics of the mobile-Internet-based individualized learning; and regards the audio-visual teaching theory and constructivist learning theory as the theoretical basis, makes the initial construction of the economics personalized learning mode based on mobile Internet. Combined with curriculum objectives, we put forward the basic goal of economics personalized learning based on mobile Internet.
\end{abstract}

\section{Introduction}

With the advance of reform and opening up, China has gradually stepped up education reform efforts, and to promote education reform through the development of a series of policies. In this context, the state promulgated the "Basic Education Curriculum Reform (Trial)", and requiring teachers to focus on individual difference and respect for differences of students, and build can guide students to actively participate in the learning of the educational environment, changes in educational methods to meet different student learning needs. Compared to traditional teaching methods, the personalized learning teaching methods not only teaching means more open, more diverse teaching mode, and its respect for individual differences of students, concerned about the students' individual learning differences and starting from individual differences of students, by to carry out various measures to diversify teaching characteristics for individual differences of students, and therefore more individualized teaching methods to improve the overall quality of students, promote the overall development of students [1].

The rapid development of mobile Internet not only to promote the transformation of education, but also a means to promote education undergone new changes, the emergence of online education, video teaching, PPT teaching both traditional means and methods of teaching have had a significant impact. Compared to traditional classroom teaching mode, the mobile-Internet-based teaching learner has the dominant position, with better timeliness, greater interactivity and better sharing features. Therefore, strengthening the teaching model to improve the mobile Internet and it will facilitate student learning inherited from the traditional turn innovative learning and individualized learning, and to promote the learning mode and educators teaching learners produce greater change.

Economics is the "Benefit the People" as its mission and practical applications are very complex subject, the purpose of teaching is to cultivate students' ability "Learning" in. Thus, not only to make students of economics teaching economics with a solid theoretical knowledge and analytical skills, but more important is to make the student in front of the complex reality, properly select and utilize the acquired knowledge and skills to analyze problems and propose reasonable and feasible 
policy recommendations. Thus, the traditional economics of innovation currently teaching mode is particularly necessary [2].

\section{Personalized Learning Meaning}

Personalized learning is accompanied by the development of education reform, a new learning theory in order to overcome the shortcomings of the traditional exam-oriented education and raised. After summarizing the relevant literature, I think: individualized teaching is student's personality traits as the basis for the student's personality and ability to full, free, harmonious development as the goal and the fact that the learning activities, the internal needs of students personalized learning core [3]. Overall, personalized learning can be summarized as the following two aspects: first, personalized attention to student learning is a process of self-fashioning and self-realization, and learning to stimulate students' learning ability, and tap the potential of students. Second, the personalized learning teaching philosophy emphasizes student-centered, according to the student's personality characteristics and development potential, individualized, in order to ensure that students free, full and harmonious development.

\section{The Meaning of Mobile-Internet-Based Individualized Learning}

Although the concept for individualized learning based on mobile Internet has not yet formed a unified definition, but academics agree that personalized learning is actually based on the mobile Internet by means of mobile Internet platform, build personalized learning network environment. Mobile Internet-based personalized learning process, students through computers, laptops, mobile Internet, IPAD Internet and other means, anywhere query, reading learning resources they need, the dominant position of the learner throughout the learning process has been true reflected.

\section{The Theoretical Basis of Mobile-Internet-Based Individualized Learning.}

Constructivist Learning Theory. Educational psychology learning theory is one of the most important theory, learning theory is to study the theory of how humans learn, it is based on mechanisms and laws of human physiology and psychology to reveal the formation process of learning, learning occurs by way of illustration, learning process, learning the law, in order to help people learn more effectively. Swiss psychologist Jean Piaget based on cognitive theory originated in the 1960s made the constructivist learning theory, learning theory believes that, in a certain social and cultural background, the learner with the help of teachers and learning partners, with some learning materials, access to knowledge through the construction of meaning. Learner's cognitive structure is in the "assimilation" and "accommodation" in the process of gradual construction, this cognitive structure in a balanced circulation system continuously enrich and improve [4].

Audiovisual Educational Theory. American education by studying how Dell's technical experts in teaching the use of audio-visual teaching methods, how to use audiovisual teaching methods produce better teaching results and other issues, summarized a series of audio-visual teaching methods, and on this basis in 1946He proposed the audiovisual educational theory. Dell through the "experience of the tower" design to describe the ways and means to gain knowledge, he will experience people get into the abstract experience, behavior, experience and observation experience three categories and you can get these three through ten ways experience. According to the introduction, "Experience Tower", the lowest level of education should start experience a gradual transition from the concrete to the abstract experience, eventually rising to abstract experience, a concept and thinking. Dell designed "tower experience" a vivid description of the experience from 
the concrete experience to rise to the development of abstract experience, in line with human understanding, understanding of the law of things, it not only forms the basis for audiovisual educational theory, but also mobile Internet Personalized Learning Teaching one of the important theory.

\section{The Basic Goal of Economics Teaching of Mobile-Internet-Based Personalized Learning.}

Economics teaching personalized mobile Internet-based learning is the use of mobile Internet platform, personalized learning economics student-centered, through student autonomy to master the knowledge requirements of economics teaching purposes. Compared with the traditional classroom, the learning approach, while teaching economics personalized mobile Internet-based learning is more flexible, more rich learning content, learning process more open; however, both the curriculum objective remains the same, they are to get the economy learn basic knowledge and skills as the goal, students correct scientific capacity and scientific spirit and values, thus improving the overall quality of students, developing students' comprehensive ability.

\section{Economics Teaching Process of Personalized Learning Based on Mobile Internet}

Teaching processes to ensure a reasonable standard is effective teaching. Mobile Internet-based learning teaching personalization, the typical teaching process is usually: teachers create situations; students into groups, assign tasks within the group; students with mobile Internet to personalize learning, to find the required data and information, and through the mobile Internet tools exchange discuss and seek solutions to solve the problem; in the course of the discussion when the need for new information and knowledge, repeatedly consult the new required information and continue discussions, if necessary empirical research must be added in order to promote solutions to problems Perfection; forming a consensus and to show the final results; and finally, the individual personalized learning to summarize, evaluate and reflect[5].

According to the above process is based on a typical mobile Internet teaching individualized learning, combined with the actual needs of the teaching of economics, to tease out the personalized mobile Internet-based learning biology teaching process: First, set up study groups, a clear mandate; secondly, to ask questions ; then packages and other offline resources, team depth analysis of the problem; then, with the necessary empirical research, the exchange of data on-line analysis, to explore cooperation in solving problems; again, to reach a consensus, to demonstrate results; Finally, summary evaluation, reflection and innovation.

\section{Conclusion}

With the current development of information technology, innovation of existing teaching methods, the introduction of mobile Internet-based personalized learning model in teaching economics, not only can enrich teaching methods to improve teaching effectiveness; and promote students can take advantage of flexible mobile Internet a variety of resources, to diversify the way students learn, to meet different students' individual learning needs; at the same time, based on the implementation of individualized learning mode mobile Internet will also allow students to personalize learning based on autonomy, through cooperative learning groups way to not only improve the ability of students to identify problems, analyze and solve problems, students select information retrieval capabilities, but also to improve the students' teamwork. Therefore, based on the mobile Internet provides a personalized learning new methods and ideas for the current economics teaching mode. 


\section{References}

[1] H.P.Lin, X.H.Tan, Suitable for large-scale networks of personalized learning Guidance System, J. Chinese education. 9(2009) 62-64.

[2] H.Yang, L.Wang, Web-based extraction algorithm personalized learning systems learner personality characteristics,J. Calculate Machine Engineering and Applications, 23(2003) 179-201.

[3] J.H.Yao, Personalized reading teaching strategies,J. Chinese teaching reference .6(2003) 26-30.

[4] L.H.Yu, F.X.Ping, "Personalized" College English Teaching Mode,J. Foreign language teaching, 12(2006) 42-44.

[5] H.Deng, Network individualized student learning characteristics of systems analysis and design,J. Journal of Distance Education,12(2006)11-13. 